\title{
Desafios e potencialidades de programas de reorientação da formação em saúde
}

\section{Challenges and potentialities of reorientation programs in health care training}

\section{Bibiana Arantes Moraes' ${ }^{1}$, Nilce Maria da Silva Campos Costa ${ }^{2}$}

${ }^{1}$ Autora para correspondência. Universidade Federal de Goiás. Goiânia, Goiás, Brasil. ORCID: 0000-0001-9312-4595. bibiananutri20@gmail.com 2Universidade Federal de Goiás. Goiânia, Goiás, Brasil. ORCID: 0000-0003-2531-1430. nilcecosta58@gmail.com

RESUMO | A formação em saúde no Brasil é norteada pelas Diretrizes Curriculares Nacionais e amparada pelos programas de reorientação da formação. Este trabalho objetivou identificar os desafios e potencialidades no processo de implementação dos programas Pró-Saúde e PET-Saúde em uma Instituição de Ensino Superior (IES) do Brasil. Foi realizado uma pesquisa social exploratória estratégica de abordagem qualitativa. Participaram deste estudo os cursos de Enfermagem, Farmácia, Medicina, Nutrição e Odontologia e, suas respectivas coordenadoras de curso de uma IES pública da região Centro-Oeste do Brasil. Aplicaram-se entrevistas semiestruturadas, que foram submetidas à análise de conteúdo na modalidade temática. A partir da análise surgiram duas categorias, desafios e potencialidades do processo de implementação de programas de reorientação da formação em saúde. Os resultados mostraram a necessidade de avançar no quesito articulação ensino/serviço/áreas de conhecimento e formação docente, mas em contrapartida foi positivo o apoio institucional, a boa relação professor/aluno, as possibilidades para melhorar a formação docente, entre outras características. Concluise que estes aspectos coexistem durante a implementação e desenvolvimento de programas que buscam pela reforma curricular e melhora na formação em saúde.

PALAVRA-CHAVE: Pesquisa qualitativa. Ensino superior. Recursos humanos em saúde.
ABSTRACT | Health education in Brazil follows the National Curricular Guidelines, and is supported by reorientation training programs. This study aimed to identify the challenges and potentialities in the process of implementation of the PróSaúde and PET-Saúde programs in an institution of higher education (IHE) in Brazil. This was a qualitative and strategic exploratory social research study. Participants in this study included Nursing, Pharmacy, Medicine, Nutrition and Dentistry courses, and their respective course coordinators in a public IHE in the Central-West region of Brazil. Semi-structured interviews were used and subjected to content analysis in the thematic modality. From this analysis, two categories emerged, challenges and potentialities of the process of implementation of reorientation programs in health care training. The results showed a need to improve in the articulation question regarding teaching / service / areas of knowledge and teacher training, but also demonstrated positive institutional support, good teacher / student relationships, possibilities for improving teacher education, among other characteristics. In conclusion, these aspects coexist during the implementation and development of programs that seek curricular reform and improvement in health care training.

KEYWORDS: Qualitative research. Higher education. Human resources in health. 


\section{Introdução}

O Ministério da Saúde (MS) e o Ministério da Educação (MEC) visando auxiliar o processo de mudança amparada pelas Diretrizes Curriculares Nacionais (DCN) no Brasil, criaram políticas indutoras de formação dos profissionais de saúde para facilitar o processo de reforma curricular das Instituições de Ensino Superior (IES). Entre eles, destacam-se o Programa Nacional de Reorientação da Formação em Saúde (Pró-Saúde) e o Programa de Educação pelo Trabalho (PET-Saúde) (Ministério da Saúde/Ministério da Educação, 2007; Ministério da Saúde/Ministério da Educação, 2008).

O Pró-Saúde propõe que a IES diagnostique suas dificuldades e evolua em direção ao aspecto desejado frente à reorientação da formação em saúde, por meio de três eixos: orientação teórica, cenários de prática e orientação pedagógica. Cada um dos eixos é disposto em três vetores que caracterizam o estado em que cada Instituição de ensino está inserida no dado momento, e o quanto deve se desdobrar para aprimorar a situação atual (Ministério da Saúde/ Ministério da Educação, 2007; Ministério da Saúde/ Ministério da Educação, 2008).

O PET-Saúde tem por finalidade viabilizar programas de aperfeiçoamento e especialização de profissionais, assim como a iniciação de estudantes nos serviços de saúde, por meio de vivências e estágios de acordo com as necessidades do Sistema único de Saúde (SUS) (Ministério da Saúde/Ministério da Educação, 2008). Apresenta escopo voltado para os cenários em que se desenvolvem o trabalho na área, e toma o SUS como ordenador da formação em saúde, em conjunto com as IES. O PET-Saúde também oferta bolsas a preceptores, tutores e acadêmicos, como um incentivo à educação permanente, pesquisa na atenção básica e vivências na prática (Ministério da Saúde/Ministério da Educação, 2008).

A efetivação de reformas curriculares por intercessão do Estado é uma tarefa árdua, pois cada IES apresenta a sua realidade, contexto, condição histórica, entre outros fatores que dificultam a reformulação curricular na prática. Assim, este estudo teve como objetivo identificar os limites e as possibilidades no processo de implementação dos programas Pró-Saúde e PETSaúde em uma IES do Brasil.

\section{Método}

Tratou-se de uma pesquisa social exploratória estratégica de abordagem qualitativa, que buscou desvelar aspectos relevantes no processo de implementação de programas de reorientação da formação em saúde, com o objetivo de melhorar a formação em saúde (Minayo, 2014).

O campo de estudo na pesquisa qualitativa é considerado um recorte espacial, que se refere ao suporte teórico, planificado a partir do objeto de investigação (Minayo, 2014). O campo deste estudo foi uma universidade pública federal localizada no estado de Goiás, Brasil. Os cursos participantes foram Enfermagem, Farmácia, Medicina, Nutrição e Odontologia, incluídas por estarem participando dos programas PróSaúde, PET-Saúde e ProPet-Saúde.

O trabalho de campo deve abranger todos os caminhos de coleta de dados, desde os referenciais teóricos até os aspectos operacionais e analíticos (Bodgan \& Biklen, 1994; Minayo, 2013). A imersão ao campo de estudo deu-se, dentro da Instituição de Ensino, em momentos adequados como reuniões, cursos e/ ou disciplinas, no qual houve a aproximação aos informantes-chaves, fato que oportunizou ao pesquisador a imersão ao campo e, consequentemente, a compreensão do fenômeno a ser estudado (Minayo, 2014; Prado, Del vale, Ortiz \& González,2008).

Para a coleta de dados foram realizadas entrevistas semiestruturadas com os cinco coordenadores dos cursos estudados, e que participaram do processo de implantação e desenvolvimento de políticas indutoras de formação em saúde da IES. As entrevistas foram realizadas com o objetivo de apreender sua experiência e vivência da realidade neste processo (Gil, 2008; Minayo, 2013).

Os coordenadores de curso foram previamente convidados a participar do estudo, com os devidos esclarecimentos e objetivos da pesquisa e, após aceitação, foi agendado horário conveniente ao participante para ser entrevistado, fato ocorrido após o consentimento e a assinatura do Termo de Consentimento Livre e Esclarecido. 
A elaboração do roteiro da entrevista semiestruturada buscou atender os objetivos do estudo em um contexto amplo e flexível, de forma a permitir a inclusão de novas questões, caso fosse pertinente, considerando a subjetividade dos sujeitos (Minayo, 2014).

Cada entrevista foi gravada e posteriormente transcrita para análise das falas, concomitantemente à coleta de dados. Foi adotada a análise de conteúdo na modalidade temática, conforme adaptação proposta por Minayo (2014).

A análise temática refere-se a como o material qualitativo se comporta em um feixe de relações, que pode ser compreendida por meio de uma palavra ou frase, que designa determinado tema que compõe uma comunicação expressa por núcleos de sentido que a posteriori torna-se objeto analítico. A operacionalização da análise temática apresentou três etapas: pré-análise (leitura flutuante, constituição do corpus e formulação e reformulação de hipóteses e objetivos), exploração do material, tratamento dos resultados obtidos, e intepretação (Minayo, 2014).

Esta pesquisa se insere no projeto "Avaliação do impacto dos Programas Pró-SAÚDE e PET-SAÚDE nos cursos de graduação da área da saúde da
Universidade Federal de Goiás", aprovada pelo Comitê de Ética em Pesquisa do Hospital das Clínicas da UFG, sob o protocolo $n^{\circ} 497.548 / 2013$ (CAAE: 23076213.6.0000.5083) e subsidiado pelo Conselho Nacional de Desenvolvimento Científico e Tecnológico do Brasil- CNPq.

Foram obedecidos os princípios e postulados éticos, com vistas a evitar qualquer possível risco e/ou constrangimento ao participante, de acordo com a Resolução CNS n 466/2012 (Resolução n 466, 2012).

\section{Resultados e discussão}

Todas os coordenadores de curso concordaram em participar da investigação. Eram do sexo feminino, trabalhavam na IES há sete anos ou mais, participaram da implementação e desenvolvimento dos programas de reorientação da formação em saúde na IES.

Ao realizar a análise das entrevistas com as coordenadoras surgiram duas categorias: 1) desafios e 2) potencialidades do processo de implementação e desenvolvimento dos programas Pró-Saúde e PETSaúde que foram dispostas no Quadro 1, com suas respectivas subcategorias:

Quadro 1. Categorias de análise das entrevistas realizadas com as coordenadoras de curso

\begin{tabular}{|l|l|l|}
\hline \multirow{2}{*}{$\mathbf{N}^{\mathbf{0}}$} & \multicolumn{2}{|c|}{ Categorias } \\
\cline { 2 - 3 } & Desafios & Potencialidades \\
\hline $\mathbf{1}$ & $\begin{array}{l}\text { Insuficiência de tempo/carga horária de docentes } \\
\text { e discentes }\end{array}$ & Possibilidade de formação docente \\
\hline $\mathbf{2}$ & Mobilização institucional insatisfatória & Participação do acadêmico bolsista \\
\hline $\mathbf{3}$ & Falta da vivência da interdisciplinaridade & Articulação ensino/serviço \\
\hline $\mathbf{4}$ & Falta de articulação ensino/serviço & Boa relação estudante/professor \\
\hline $\mathbf{5}$ & $\begin{array}{l}\text { Falta de integração políticas/cursos/áreas de } \\
\text { conhecimento }\end{array}$ & Apoio institucional \\
\hline $\mathbf{6}$ & Falta de formação docente & \\
\hline $\mathbf{7}$ & Não diversificação dos cenários de prática & \\
\hline
\end{tabular}




\section{Desafios do desenvolvimento de programas de reorientação da formação em saúde}

Observou-se ao analisar as falas das coordenadoras de curso, algumas dificuldades durante o processo de implementação e desenvolvimento dos programas Pró-Saúde e PET-Saúde como a insuficiência de tempo/carga horária de docentes e discentes; mobilização institucional insatisfatória; falta de vivência da interdisciplinaridade; articulação ensino/serviço; integração de políticas, cursos e áreas de conhecimento; formação docente e, há não diversificação dos cenários de prática.

\section{- Insuficiência de tempo/carga horária de docen- tes e discentes}

A falta de tempo e adequação da carga horária foram relatadas como prejudiciais ao processo de reforma curricular, seja para os professores reunirem-se para discutir as questões curriculares em atividades integradas entre a universidade e os serviços de saúde e/ou em reuniões dos tutores com os discentes bolsistas:

"[...] é uma questão de tempo de conseguir dedicar realmente para esta restruturação". (E1)

"Nesse último PET, eu fiz reuniões na minha casa, dia de sábado, porque não há possibilidade de ter horários comuns". (E5)

A reestruturação curricular e/ou mudanças na formação em saúde necessitam de discussões, reuniões e apontamentos importantes para os cursos, além de tempo hábil para docentes e/ou discentes se articularem. Porém, o grande número de atividades desenvolvidas e a incompatibilidade de horários, contribuem para comprometer o processo de implementação do Pró-Saúde/PET-Saúde e a reforma curricular (Costa, 2007; Fonseca \& Junqueira, 2014; Mendonça, Cotta, Lelis \& Carvalho Junior, 2015).

\section{- Mobilização institucional insatisfatória}

A mobilização institucional insatisfatória prejudicou o processo de mudança da formação em saúde e o Pró-Saúde e PET-Saúde de não terem sido assumidos como uma política governamental de formação:
"[...] a gente tem muitos avanços nesse processo de formação, mas não na velocidade e na facilidade que a gente queria". (E2)

"O Pró-Saúde não foi assumido como uma política de formação, de mudança do processo de formação".(E2)

"Em alguns momentos, a própria secretaria municipal não entendia muito bem o seu papel como gestor da educação permanente". (E2)

"O tutor tem remuneração e o supervisor de estágio não tem. Então em alguns sentidos acaba gerando uma dificuldade, porque eles questionam porque um recebe e o outro não recebe". (E1)

"[...] até hoje, há pouco entendimento por parte dos professores, sobre o que preveem as Diretrizes Curriculares". (E2)

"A maioria das pessoas (professores), não sabe o que está escrito no projeto [Propet]". (E5)

A falta de mobilização institucional dificulta o processo de reforma curricular e mudança da formação profissional em saúde, pois, sem o apoio institucional, os cursos não conseguem a disponibilidade necessária para atingir os objetivos traçados e a pouca articulação com os cursos e com o serviço inviabiliza os processos teoria/prática, integração entre os cursos e ensino/serviço (FRENK et al., 2010).

Os estudos de Bomfim, Goulart \& Oliveira (2014) e Toassi, Souza, Baumgarten \& Rossing (2012) demonstraram que os alunos e docentes não tinham o conhecimento sobre o PPC ou que não foi disponibilizado o documento por parte da instituição. Questiona-se: como é possível formar profissionais de saúde pautados nos preceitos do SUS e conforme as DCN, se os docentes, discentes e/ou serviço de saúde desconhecem os documentos norteadores da formação que os rege?

O descompasso observado poderá ser revertido, dentro das instituições formadoras em saúde, quando houver o reconhecimento das políticas indutoras de formação em saúde como incentivo para alcançar as prerrogativas das DCN e do SUS e a formação da comunidade acadêmica quanto às legislações correlatas.

O docente em saúde necessita romper com as disciplinas no formato de grades para ser provocador de mudanças. Portanto, atitudes como conhecer o currículo, a legislação que norteia a formação em saúde, 
as diferentes abordagens de ensino, sensibilizar-se quanto a educação permanente, se envolver na tríade ensino-pesquisa-extensão e adotar instrumentos avaliativos inovadores, são necessárias para desenvolver o senso crítico e reflexivo dos discentes (Bravo, Cyrino \& Azevedo, 2014).

A lentidão é uma característica do processo de reforma educacional, pois mudar exige ações processuais e tempo para que os avanços possam ser assimilados e compreendidos pelos atores sociais e assim, possa ser efetivada a mudança necessária. Daí a importância da avaliação curricular constante, como precursora relevante da necessidade ou não de mudar (Toassi, Souza, Baumgarten \& Rossing, 2012).

\section{- Falta da vivência da interdisciplinaridade}

Promover a integração de conteúdos e entre as disciplinas foi apontado como um limite a ser superado:

"Há dificuldade do professor de fazer o que está no papel, promover a interdisciplinaridade, promover a integração de conteúdos, uma integração mais efetiva".

Há uma hipótese de que o currículo organizado em disciplinas impede e/ou dificulta o processo de interdisciplinaridade, pois as áreas de conhecimento encontram-se fracionadas. E esta disposição dos saberes fragmentados condiciona a formação tecnicista, curativista e biologicista (Rodrigues, Rocha, Anjos, Cavalcante \& Rozendo, 2013; Silveira \& Garcia, 2015).

O estudante fica condicionado ao ensino tradicional, e apresenta dificuldades na relação interdisciplinar e multidisciplinar necessária para formação em saúde. Normalmente há uma preferência por disciplinas teóricas e específicas ao longo da graduação, com pouca aceitabilidade de atividades que envolvam outros saberes ou questões de cunho político-social (Leite, Rodrigues, Mendes, Veloso, Andrade \& Rios, 2012; Silveira \& Garcia, 2015; Moraes \& Costa, 2016; Moraes \& Costa, 2018).

\section{- Falta de articulação ensino/serviço}

A interação ensino/serviço em alguns momentos foi prejudicada, pois, nem sempre há um supervisor no campo prático e/ou o professor que consegue desenvolver seu planejamento de aula no serviço de saúde:
"[...] há um pouco dessa dificuldade, do aluno desenvolver, de ter supervisor lá na prática, que recebam o estudante, que atendam. Locais de prática que realmente consigam ofertar aquilo que a gente planeja na disciplina". (E4)

A articulação ensino/serviço auxilia no processo de construção de conhecimento, sem ela não seria possível compreender a prática e a dinâmica do trabalho (Albuquerque et al. 2013).

Sobral (2014) realizou análise das primeiras propostas inovadoras do ensino médico de três IES do Brasil, com intuito de verificar se as mesmas estavam formando médicos voltados para as necessidades de saúde e para o cenário comunitário. Notou-se que a articulação ensino-serviço e o envolvimento comunitário no planejamento e implementação de programas tiveram grau mínimo ou nenhuma orientação comunitária nas três IES, denotando a dificuldade de interação da comunidade e do serviço com o processo formativo do estudante.

Fadel \& Baldani (2013) ao analisarem a percepção de formandos do curso de odontologia obtiveram como satisfatório e/ou ideal (em torno de 50\%): integração entre as disciplinas do curso, inter-relação entre os conhecimentos das disciplinas básica e clínicas, e articulação entre a teoria e prática. A partir destes resultados é possível refletir que o currículo em saúde aos poucos se desloca de uma postura biologista, fragmentada, para um currículo integrado e articulado. Neste estudo, no entanto, está ainda aquém do desejável.

\section{- Falta de integração de políticas/cursos/áreas de conhecimento}

Existiu a dificuldade de balizar as propostas das políticas indutoras de reorientação da formação em saúde e das DCN com as ações, atividades e/ou disciplinas dos cursos, e com suas áreas de ensino/conhecimento, mesmo quando estas estão inseridas no currículo. Os cursos de graduação e projetos de mudanças da formação em saúde ainda são executados isoladamente:

"[...] as disciplinas hoje têm propostas de integração, porém, ainda continua o professor daquela especialidade. A gente não consegue tirar isso do professor". (E2) 
"[...] cada PET trabalhou isoladamente, embora a gente tenha feito reunião para prestar conta, para discutir, para não sei o quê, não houve bem uma integração". (E5)

"[...] percebe-se um pouco, a parte de gestão do estudante é objetivo que a gente tem lá descrito. E que a gente tem avaliado que talvez a gente tenha que reforçar um pouco mais". (E4)

Leal, Melo, Veloso \& Juliano (2015) e Fadel \& Baldani (2013) também apontaram para a competência/habilidade gestão em saúde como uma lacuna presente na formação das IES. A justificativa para esse déficit pode ser explicada pelo fato de que os currículos carecem de disciplinas que reconheçam os profissionais de saúde como gestores.

Apesar das propostas curriculares serem baseadas em políticas indutoras da formação em saúde e proporem a integração dos cursos/conhecimento, os currículos apresentam no PPC propostas inclusivas e compartilhadas, mas, na prática apresentam um currículo fechado, especializado e alienado, o que dificulta a interação entre os profissionais e o trabalho em equipe (Almeida Filho, 2013; Pereira, 2017).

Almeida Filho (2013) apontou várias dificuldades a serem superadas no ensino superior em saúde no Brasil como: pouco conhecimento e compromisso com SUS; compreensão de trabalho em equipe multiprofissional, integração de conhecimentos interdisciplinares, fraca formação humanista, pouca maturidade para o exercício da profissão, resistência a mudanças, entre tantas outras dificuldades, o que viabiliza o status quo preexistente do cuidado do sistema de saúde vigente (Almeida Filho, 2013).

\section{- Falta de formação docente}

No quesito formação docente, foi citada a dificuldade de lidar com metodologias ativas de ensino e de operacionalizar métodos de ensino à distância:

\section{"[...] os professores e os estudantes tem dificuldades em acessar a plataforma (moodle)". (E3)}

Apesar do uso dos computadores e internet estar bem consolidado, ainda há pouca familiaridade com os métodos de ensino e com tecnologias de informação. Há dificuldade de operacionalizar os ambientes virtuais como ferramentas de aprendizagem sob o prisma de um movimento reflexivo, sendo ainda um desafio a ser superado (Lima, Feuerwerker, Padilha, Gomes \& Hortale, 2015).

A maioria dos docentes foram formados com a concepção cartesiana e tecnicista, o que dificulta a atuação docente frente a demanda das DCN e das políticas de reorientação da formação em saúde:

"Apesar de ter atendido as diretrizes, era um currículo que causava estranhamento no professor, porque o professor não se via naquilo, ele detinha um conhecimento que era bem fragmentado, era bem especializado e ele não sabia como é que faria essa integração desse conhecimento [...]. Os professores têm muita visão curativista da prática". (E2)

\section{"[...] transformar um currículo que está caminhando} não é fácil, pela formação do corpo docente". (E4)

Os cursos de saúde no Brasil são historicamente marcados pela concepção flexneriana, no qual há um predomínio da atuação hospitalocêntrica, curativista e biologicista. Essa raiz histórica encontra-se em alguns espaços engessado no modelo de formação que os docentes e discentes estão condicionados, eles apresentam dificuldades de aceitar outro modelo de formação, que seja pautado em um processo de aprendizagem formativa, interdisciplinar e multidisciplinar (Mendonça, Cotta, Lelis \& Carvalho Junior, 2015; Silveira \& Garcia, 2015). Busca-se a partir de iniciativas de formação docente uma ruptura paradigmática de um novo professor, docente e comunidade acadêmica.

\section{- Não diversificação dos cenários de prática}

A diversificação dos cenários de prática não acontece como desejado devido à carga horária dos cursos:

"Uma das principais fragilidades que nós temos é a diversificação dos cenários de prática, pois, nós temos uma carga horária muito pequena". (E2)

A comunidade acadêmica ao construir os currículos em saúde deve adequar a carga horária às atividades práticas e buscar a diversificação dos cenários de prática, pois, estes auxiliam na compreensão teórico/ prática e desenvoltura do estudante na futura atividade profissional. Posteriormente, poderá realizar educação permanente nas áreas de maior pertinência ou que não foram suficientemente esgotadas durante a graduação (Nóbrega-Therrien, Souza, Pinheiro \& Castro, 2015). 


\section{Potencialidades no desenvolvimento de programas de reorientação da formação em saúde}

Ao implementar os programas de reorientação da formação em saúde na instituição de ensino estudada também foi possível verificar potencialidades durante esse processo, como a formação docente, participação do aluno bolsista, a articulação ensino/ serviço, a boa relação professor/aluno e o apoio institucional. Alguns destes apresentaram sob determinadas características como limitador e/ou possibilidade no desenvolvimento dos programas.

\section{- Possibilidade de Formação docente}

Os auxílios financeiros disponibilizados pelos programas de reorientação da formação em saúde foram um importante benefício para que ocorressem atividades formadoras como oficinas, consultorias e capacitações:

"A questão do apoio financeiro do programa tem nos auxiliado, em relação a propiciar oficinas e algum tipo de consultoria". (E1)

A formação docente apresentou-se como facilitadora do processo de mudança da formação em saúde, pela estimulação de lideranças que conseguiram estimular outros professores:

"[...] muita das ações do Pró-Saúde foram feitas em função dos professores, de quem acreditava nesse próprio processo mudança". (E2)

"A facilidade sempre é a questão da liderança de um grupo de professores que acreditam que essas mudanças foram necessárias". (E3)

O Pró-Saúde teve como um dos propósitos subsidiar financeiramente a formação docente, por meio de oficinas, consultorias, cursos, entre outros, para que os professores tivessem domínio de abordagens pedagógicas como metodologias de ensino inovadoras, métodos de avaliação, entre outras. Redefinindo a forma preconcebida do docente de ensinar, passando este a ser facilitador do processo de ensino-aprendizagem e não mais o detentor do conhecimento (Ministério da Saúde/Ministério da Educação, 2007).

Ferreira, Fiorini \& Crivelaro (2010) obtiveram relatos semelhantes ao encontrados nesta pesquisa, em que o docente surgiu como facilitador do processo de formação para o SUS. Os autores assinalam a busca por professores que estimulem seus educandos a construir o conhecimento a partir da busca de informações, leituras, reflexões e críticas que levem o discente a sanar situações problemas encontrada na realidade, ou seja, o professor atuará como facilitador na construção do processo de ensino-aprendizagem.

\section{- Participação do aluno bolsista}

Os programas de reorientação da formação em saúde se mostraram como incentivo à formação dos discentes, pois, oportunizava cargas horárias menores em relação a outros projetos com:

"[...] são programas com bolsa [...] que demandam uma carga horária menor do aluno em relação à uma iniciação científica ou extensão". (E1)

Os discentes vinculados aos programas de reorientação da formação em saúde obtiveram novas oportunidades práticas de conhecimento e a carga horária exigida conseguiu contribuir com o desenvolvimento formativo do discente, não prejudicando às outras atividades curriculares (Ministério da Saúde/ Ministério da Educação, 2005; Ministério da Saúde/ Ministério da Educação, 2008).

\section{- Articulação ensino/serviço}

A IE estudada sempre teve boa articulação com os serviços de saúde e o movimento de mudança da formação em saúde trouxe ganhos para ambos. A instituição inseriu alunos do PET-Saúde no serviço e os docentes puderam estreitar a aproximação com o sistema de saúde. Em contrapartida o serviço recebeu mais alunos para ajudar no trabalho e cursos foram ministrados aos profissionais da rede de saúde, aumentando a articulação ensino/serviço:

"Nós treinamos nossos alunos juntos com os técnicos do serviço. Os alunos vão até lá, ajudam no trabalho, aprendem com os técnicos". (E5)

"Eu acho que vários professores conseguiram se articular melhor dentro do sistema de saúde". (E5)

"Eu acho que naquele primeiro momento, era mesmo uma falta de compreensão da dimensão do que é o SUS educador [...] Hoje, isso está mais estabelecido, agora tem a escola de saúde pública do município". (E2) 
As DCN preconizam profissionais voltados para realidade do sistema de saúde vigente, este objetivo só é possível mediante os profissionais conhecerem o funcionamento, políticas, profissionais e a comunidade presentes no SUS (Parecer $n^{\circ} 1.133,2001$ ).

A efetivação do aprendizado é mediada pela ação e execução da prática. A oportunidade de trabalhar dentro do serviço de saúde desde o início da formação estimula o aprendizado construído na sala de aula e dá margem à que os alunos apreendam, a partir da observação do serviço e da atuação dos profissionais e, à medida em que conseguem adquirir habilidades passam a executar atividades no serviço com graus de complexidade de acordo com a capacidade desenvolvida, fato que contribui para o desenvolvimento da autonomia ao longo da formação (Parecer $n^{\circ}$ 1.133, 2001; Leal, Melo, Veloso \& Juliano, 2015).

A Secretaria Municipal de Saúde (SMS), com o incentivo das políticas indutoras de reorientação da formação em saúde, montaram uma escola de saúde pública no intuito de fomentar a educação permanente (EP) para seus profissionais de saúde da SMS, conforme relato da coordenadora de curso, o que demonstrou preocupação da instituição em adequar o atendimento prestado conforme as necessidades do sistema de saúde vigente.

A interação ensino-serviço é fundamental, pois, apenas a competência técnica não garante a especificidade necessária para questões de cunho social e de abordagem integral do sujeito. E o serviço de saúde fornece ao estudante oportunidades de efetivar a relação teoria/prática além de especificidades advindas com a realização do trabalho no campo real (Silveira \& Garcia, 2015).

\section{- Boa relação aluno/professor}

A relação aluno/professor foi facilitadora do processo, pois, contribui para aprendizagem:

"A relação com os alunos é muito boa no geral, nós somos próximos, isso eu acho que ajuda [...]. Nessa aprendizagem não formal é muito importante". (E5)

O estabelecimento da relação aluno/professor auxilia na aprendizagem, espaços agradáveis, de respeito e com bom diálogo oportunizam criar vínculos e os acadêmicos sentem abertura para discutir não apenas questões da aprendizagem, mas posicionarem-se como sujeitos de mudança da formação, com sugestões de melhoria e desenvolvimento para o curso (Toassi, Souza, Baumgarten \& Rossing, 2012).

O processo de reformulação da formação é composto por um conjunto de pessoas, que acreditam serem necessárias mudanças no ensino. Não é possível efetivar a reorientação da formação sem a interação de pessoas, grupos, e /ou atores sociais dentro do processo, por isso o bom envolvimento entre eles, as relações interpessoais são de grande relevância para a superação da fragmentação do ensino (Lima, Feuerwerker, Padilha, Gomes \& Hortale, 2015).

\section{- Apoio institucional}

Ao tratar do apoio institucional, o primeiro edital do Pró-Saúde foi o que obteve maior incentivo, e proporcionou atividades articuladas:

“O primeiro edital do Pró-Saúde ele [...] teve um apoio institucional maior. Nós tivemos muito mais força no sentido de fazer atividades conjuntas". (E2)

Segundo o relato das entrevistadas, as políticas indutoras de reorientação da formação em saúde obtiveram maior respaldo institucional no seu início, posteriormente as lideranças perderam força e/ou motivação por parte dos atores sociais. É imprescindível o papel das lideranças e da comunidade acadêmica em apoiar as IE no processo de reforma curricular e/ou mudanças desta instância, para que motivem a liderança, caracterizada em sua maioria pelos próprios membros da comunidade acadêmica (Pereira, 2017; Moraes \& Costa, 2016).

Moraes e cols (2019) ao realizarem a percepção dos atores envolvidos no Propet-Saúde sobre a reestruturação curricular dos cursos de graduação da área da saúde da UFG, a formação em saúde demonstrou seu caráter multifatorial, apontando aspectos de infraestrutura, respeito ao tempo de mudança, atores estimulados para avanços e apropriação das políticas existentes com tradução nos currículos vigentes, sendo esses programas importantes para reformulação da formação em saúde e seu estímulo de continuidades nas IES. 


\section{Conclusão}

Ao analisar as falas das coordenadoras de curso surgiram duas grandes categorias, desafios e possibilidades a partir do desenvolvimento dos programas Pró-Saúde e PET-Saúde na IES estudada.

Os desafios foram conhecidos pela insuficiência de tempo/carga horária de docentes e discentes, mobilização institucional insuficientes, falta de vivência da interdisciplinaridade, de articulação ensino/serviço, de integração de políticas/cursos/áreas de conhecimento e de formação docente. E surgiram como potencialidades a formação docente, participação do acadêmico bolsista, articulação ensino/serviço, boa relação estudante/professor e o apoio institucional.

Percebe-se que a articulação ensino/serviço e formação docente surgiram em ambas categorias, nos limites quanto nas possibilidades. É possível inferir que estas passam por um processo de implementação e que em algumas situações apresentavam como limite a ser superado ou possibilidades que auxiliaram na reforma curricular ancorados nos programas de reorientação da formação em saúde.

Ao refletir sobre os aspectos encontrados como limites e possibilidades do desenvolvimento do PróSaúde e PET-Saúde na IES estudada a partir da perspectiva dos coordenadores de curso, percebe-se que os aspectos encontrados são de relevância local, mas coexistem em outras realidades institucionais, pois muitas destas características estão retratadas pela literatura, e em outras IES no Brasil.

Verificou-se que a implementação dos programas de reorientação da formação em saúde ainda está em desenvolvimento e não conseguiu atender a todos os quesitos dispostos em suas bases norteadoras. Não se pode deixar de considerar os valores, historicidade, assimilação, questões político-sociais, entre outros motivos ainda não esclarecidos, sendo necessário o estímulo a novos estudos desta natureza, com vistas a buscar uma formação em saúde cada vez mais próxima da realidade almejada pelas $D C N$ e pelos princípios do SUS.

E a partir das potencialidades encontradas faz-se necessário o estímulo de continuidade destes programas, apoio institucional e governamental para que estas propostas deem continuidade e contribuam para melhora da formação em saúde.

\section{Agradecimentos}

Esta pesquisa foi subsidiada pelo conselho nacional de desenvolvimento científico e tecnológico - CNPq (edital nº 13/2013) e apoio da coordenação de aperfeiçoamento de pessoal de nível superior - capes, entidade do governo brasileiro voltada para a formação de recursos humano. Agradecemos à Instituição de Ensino estudada e as coordenações de curso por disponibilizarem os PPC utilizados nesta pesquisa.

Este artigo é resultado de pesquisa aprovada para apresentação no $7^{\circ}$ Congresso Ibero-Americano em Investigação Qualitativa - CIAIQ, realizado de 10 a 13 de julho de 2018 em Fortaleza, Ceará, Brasil.

\section{Contribuições das Autoras}

Moraes, B. A. foi responsável pela estruturação teórica, coleta e análise de dados da pesquisa. Atuou na escrita do artigo em questão e este é um dos produtos da dissertação de mestrado da autora. Costa, N. M. S. C. foi orientadora de mestrado, responsável pela escrita geral do projeto, auxiliou no tratamento e a análise dos dados. Atuou na escrita do artigo e em sua revisão.

\section{Conflitos de Interesses}

Nenhum conflito financeiro, legal ou político envolvendo terceiros (governo, empresas e fundações privadas, etc.) foi declarado para nenhum aspecto do trabalho submetido (incluindo, mas não limitando-se a subvenções e financiamentos, participação em conselho consultivo, desenho de estudo, preparação de manuscrito, análise estatística, etc.).

\section{Referências}

Albuquerque, G. S. C., Torres, A. A. R., Nascimento, B., Martin, B. M., Gracia, D. F. K., Orlando, J. M. M., ... Perna, P. O. (2013). Educação pelo trabalho para a formação do médico. Trabalho, educação e Saúde, 11(2), 411-430. Recuperado de http://www.scielo.br/pdf/tes/v11n2/a09v11n2.pdf. doi: 10.1590/S1981-77462013000200009

Almeida Filho, M. N. (2013). Contexts, impasses and challenges for training Public Health workers in Brazil. Ciência e saúde coletiva, 18(6), 1677-1682. Recuperado de http:// www.scielo.br/pdf/csc/v18n6/19.pdf. doi: 10.1590/S1413$\underline{81232013000600019}$

Bodgan, R. C., \& Biklen, S. K. (1994). Investigação qualitativa em educação: uma introdução à teoria e aos métodos. Porto: Porto Editora.

Bomfim, M. I., Goulart, V. M. P., \& Oliveira, L. Z. (2014). Teacher education in health: assessment, issues and tensions. Interface: comunicação, saúde e educação, 18(51), 749758. Recuperado de http://www.scielo.br/pdf/icse/ v18n51/1807-5762-icse-18-51-0749.pdf. doi: 10.1590/180757622013.0974 
Costa, N. M. S. C. (2007). Docência no ensino médico: porque é tão difícil mudar? Revista Brasileira de Educação Médica, 31(1), 21-30. Recuperado de http://www.scielo.br/pdf/rbem/ v31n1/04.pdf. doi: 10.1590/S0100-55022007000100004

Fadel, C. B., \& Baldani, M. H. (2013). Percepções de formandos do curso de odontologia sobre as Diretrizes Curriculares Nacionais. Trabalho, educação e saúde, 11(2), 339-354. Recuperado de http://www.scielo.br/pdf/tes/v11n2/ a05v11n2.pdf. doi: 10.1590/S1981-77462013000200005

Ferreira, R. C., Fiorini, V. M. L., \& Crivelaro, E. (2010). Formação profissional no SUS: o papel da atenção básica em saúde na perspectiva docente. Revista Brasileira de Educação Médica, 34(2), 207-215. Recuperado de http://www.scielo. br/pdf/rbem/v34n2/a04v34n2.pdf. doi: 10.1590/S010055022010000200004

Fonseca, G. S., \& Junqueira, S. R. (2014). Programa de Educação pelo Trabalho para a Saúde da Universidade de São Paulo (Campus Capital): o olhar dos tutores. Revista Ciência e Saúde Coletiva, 19(4), 1151-1162. Recuperado de http:// www.scielo.br/pdf/csc/v19n4/1413-8123-csc-19-04-01151. pdf. doi: 10.1590/1413-81232014194.00192013

Gil, A. C. (2008). Métodos e técnicas de pesquisa social. São Paulo: Altas.

Leal, J. A. L., Melo, C. M. M., Veloso, R. B. P., \& Juliano, I. A. (2015). New reorientation spaces for healthcare education: students' experiences. Interface: comunicação, saúde e educação, 19(53), 361-371. Recuperado de http://www. scielo.br/pdf/icse/v19n53/1807-5762-icse-19-53-0361.pdf. doi: 10.1590/1807-57622014.0107

Leite, M. T. S., Rodrigues, C. A. Q., Mendes, D. C., Veloso, N. S., Andrade, J. M. O., \& Rios, L. R. (2012). O Programa de Educação pelo Trabalho para a Saúde na formação profissional. Revista Brasileira de Educação Médica, 36(Suppl.1), 111-118. Recuperado de http://www.scielo.br/ pdf/rbem/v36n1s1/v36n1s1a15.pdf. doi: 10.1590/s010055022012000200015

Lima, V. V., Feuerwerker, L. C. M., Padilha, R. Q., Gomes, R., \& Hortale, V. A. (2015). Ativadores de processos de mudança: uma proposta orientada à transformação das práticas educacionais e da formação de profissionais de saúde. Ciência e saúde coletiva, 20(1), 279-288. Recuperado de http://www.scielo.br/pdf/csc/v20n1/ pt_1413-8123-csc-20-01-00279.pdf. doi: 10.1590/141381232014201.21992013

Mendonça, E. T., Cotta, R. M. M., Lelis, V. P., \& Carvalho Junior, P. M (2015). Paradigms and trends in higher education: the action research methodology as a teacher education strategy. Interface: comunicação, saúde e educação, 19(53), 373-386. Recuperado de http://www.scielo.br/pdf/icse/ v19n53/1807-5762-icse-19-53-0373.pdf. doi: 10.1590/180757622013.1024
Minayo, M. C. S. (2013). Trabalho de campo: contexto de observação, interação e descoberta. In M. C. S. Minayo, S. F. Deslandes, \& R. Gomes. Pesquisa social: teoria, método e criatividade (pp. 61-78). Petrópolis: Vozes.

Minayo, M. C. S. (2014). O desafio do conhecimento: pesquisa qualitativa em saúde. São Paulo: Hucitec.

Ministério da Saúde. Ministério da Educação. (2007). Programa Nacional de Reorientação da Formação Profissional em Saúde - Pró-Saúde: objetivos, implementação e desenvolvimento potencial. Brasília: Autor. Recuperado de http://bvsms. saude.gov.br/bvs/publicacoes/07_0323_M.pdf

Moraes, B. A., \& Costa, N. M. S. C. (2016). Compreendendo os currículos à luz dos norteadores da formação em saúde no Brasil. Revista da Escola de Enfermagem da Universidade, 50(n. esp.), 9-16. Recuperado de http://www.scielo.br/pdf/ reeusp/v50nspe/pt_0080-6234-reeusp-50-esp-0009.pdf. doi: 10.1590/S0080-623420160000300002

Moraes, B. A., \& Costa, N. M. S. C. (2018). A implementação de programas de reorientação da formação em saúde em uma instituição de ensino superior no Brasil. Atas Congresso Ibero-Americano em Investigação Qualitativa. Fortaleza, CE, Brasil, 7. Recuperado de https:// proceedings.ciaiq.org/index.php/ciaiq2018/article/ view/1832/1783

Moraes, B. A., Sousa, L. M., Menezes, I. H. C. F., Queiroz, M. G., Costa, N. M. S. C., Guimarães, M. M., ... Ferreira, B. J. (2019). Avaliação do Impacto dos Programas de Reorientação Profissional em Cursos da Área da Saúde. Revista Brasileira de Educação Médica, 43(2) 122-129. Recuperado de http://www.scielo.br/pdf/rbem/v43n2/1981-5271rbem-43-2-0122.pdf. doi: 10.1590/1981-52712015v43n2 rb20180162

Nóbrega-Therrien, S. M., Souza, P. M. M., Pinheiro, F. M. C., \& Castro, V. S. (2015). Profissional no SUS: o papel da atenção básica em saúde na perspectiva docente. Revista Brasileira de Educação Médica, 39(1) 112-118.

Parecer $n^{\circ} 1.133$, de 7 de outubro de 2001. Dispõe as Diretrizes Curriculares para os cursos de graduação de Enfermagem, Medicina e Nutrição.

Pereira, A. (2017). Avaliação e reformulação de currículo: relações que se (des)encontram na prática. E-curriculum, 15(2), 293-324. Recuperado de https://revistas. pucsp.br/curriculum/article/view/13597/23097. doi: 10.23925/1809-3876.2017v15i2p293-324

Portaria interministerial $n^{\circ} 1.802$, de 26 de agosto de 2008. Institui o Programa de Educação pelo Trabalho para a Saúde PET-saúde. Recuperado de http://bvsms.saude.gov.br/bvs/ saudelegis/gm/2008/pri1802_26_08_2008.htm 
Prado, M. L., Del vale, A. M. Q., Ortiz, L. G. C., \& González, E. L. (2008). El diseño en la investigación cualilativa. In M. L. Prado, M. L. Souza, \& T. E. Carraro. Investigación cualitiva en enfermeira: contexto y bases conceptuais. Washington: Organización Panamericana de La Salud, 1-20.

Resolução $n^{\circ}$ 466, de 12 de dezembro de 2012. Aprova as diretrizes e normas regulamentadoras de pesquisas envolvendo seres humanos. Recuperado de http://bvsms.saude.gov.br/bvs/ saudelegis/cns/2013/res0466_12_12_2012.html

Rodrigues, J. A., Rocha, L. S., Anjos, D. S., Cavalcante, L. P. F., \& Rozendo, C. A. (2013). Tendências Pedagógicas: conflitos, desafios e perspectivas de docentes de enfermagem. Revista Brasileira de Educação Médica, 37(3), 333-349. Recuperado de http://www.scielo.br/pdf/rbem/v37n3/05. pdf. doi: 10.1590/S0100-55022013000300005

Silveira, J. L. G. C., \& Garcia, V. L. (2015). Curricular change within dentistry: meanings according to the subjects of the learning. Interface, 19(52), 145-158. Recuperado de http://www.scielo.br/pdf/icse/v19n52/1807-5762icse-19-52-0145.pdf. doi: 10.1590/1807-57622014.0530

Toassi, R. F. C., Souza, J. M., Baumgarten, A., \& Rosing, C. K. (2012). Avaliação curricular na educação superior em odontologia: discutindo as mudanças curriculares na formação em saúde no Brasil. Revista da ABENO, 12(2), 170-177. Recuperado de https://revabeno.emnuvens. com.br/revabeno/article/view/120/111. doi: 10.30979/rev. abeno.v12i2.120 